\title{
Helicopter Main Gearbox Bearing Defect Identification with Acoustic Emission Techniques
}

\author{
Fang Duan*, Faris Elasha ${ }^{\dagger}$, Matthew Greaves ${ }^{\ddagger}$ and David Mba ${ }^{\S}$ \\ * School of Engineering, London South Bank University \\ London, SE1 0AA, UK, Email: duanf@1sbu.ac.uk \\ ${ }^{\dagger}$ Faculty of Engineering, Environment and Computing, Coventry University \\ Coventry, CV1 5FB, UK, Email: faris.elasha@ coventry.ac.uk \\ ${ }^{\ddagger}$ School of Aerospace, Transport, and Manufacturing, Cranfield University \\ Bedford, MK43 0AL, UK, Email: m.j.greaves@Cranfield.ac.uk \\ ${ }^{\S}$ School of Engineering, London South Bank University \\ London, SE1 0AA, UK, Email: mbad@1sbu.ac.uk
}

\begin{abstract}
Helicopter transmission integrity is critical to the safety operation. Among all mechanical failures in helicopter transmission, the main gearbox (MGB) failures occupy approximately $16 \%$. Great effort has been paid in early prevention and diagnosis of MGB failures. As a commonly employed monitoring technology, vibration analysis suffers from strong background noise due to variable transmission paths from the bearing to the receiving externally mounted vibration sensor. The background noise can mask the signal signature of interest. This paper reports on an investigation to identify the presence of a bearing defect in a CS29 Category ' $A$ ' helicopter main gearbox with acoustic emission (AE) technologies. This investigation involved performing the tests for faultfree condition, minor bearing damage and major bearing damage conditions under different power levels. The bearing faults were seeded on one of the planet gears of the second epicyclic stage. To overcome the issue of low signal to noise ratio (SNR), AE sensor was directly attached on the dish of planet carrier. The AE signal was transferred wireless to avoid complex wiring inside MGB. The analysis results proved the feasibility of using AE sensor as in-situ bearing defect identification.
\end{abstract}

Index Terms-Helicopter main gearbox, acoustic emission, bearing defect diagnostics .

\section{INTRODUCTION}

$\mathbf{T}$ HE main gearbox (MGB) is one of the most critical parts of helicopter. During flight, MGB suffers from high temperature and stress as a substantial amount of frictional heat is generated when the input high rotation speed of gas turbines is converted to low speed, high torque within MGB. The malfunction of the MGB can cause serious disaster due to the lack of redundancy of transmission system in helicopter [1]. The operating condition of MGB is usually monitored by using vibration and temperature sensors in helicopter health and usage monitoring systems (HUMS). These sensors are usually

The research is conducted under the project contract European Aviation Safety Agency (EASA), EASA.2012.OP.13, entitled "VHM - Vibration health or alternative monitoring technologies for helicopters". mounted on casing to avoid complex wiring. However, vibration signal might be significantly attenuated if target bearing or gear is far from gearbox housing. The indirect measurement could not provide accurate temperature as previous research showed the large thermal gradients between the gear and ambient [2].

In addition to external vibration analysis, internal acoustics emissions (AE) technology is also employed to identify a fault condition. AE provides the benefit of early fault detection in comparison to vibration analysis and oil analysis because of the high sensitivity to friction offered by AE [3], [4]. AE sensors detects stress wave that propagates through the material when crack surfaces are formed. As the crack propagates, the frequency of the stress wave increases and these activities are monitored by the $\mathrm{AE}$ sensor. As such, $\mathrm{AE}$ is suitable for detecting early stages of crack initiation. Ideally, AE sensor has to be close to its source to avoid severe attenuation and reflections. However, it is often only practical to place $\mathrm{AE}$ sensor on the non-rotating parts of the machine, such as the bearing housing or gearbox casing. In order to solve the aforementioned issues of indirect measurement and complex wiring inside MGB, AE sensor was directly attached on the target bearing and the acquired signal was wirelessly transmitted in this study. Minor and major faults were seeded on the outer race and inner race of second-stage planet gears of a CS-29 Category A helicopter gearbox. The test was conducted under low, medium and high power conditions. To the best knowledge of authors, this is the first time that $\mathrm{AE}$ technology has been applied to identify a fault condition where the AE signature of interest is severely masked by the presence of gear meshing AE noise. The results clearly showed defect frequencies for all defect conditions and power conditions.

\section{EXPERIMENTAL RIG}

A SA 330 Puma helicopter MGB was utilized to investigate the feasibility of bearing defect detection using AE sensor. The MGB consists of five reduction gear modules (RGMs), left 


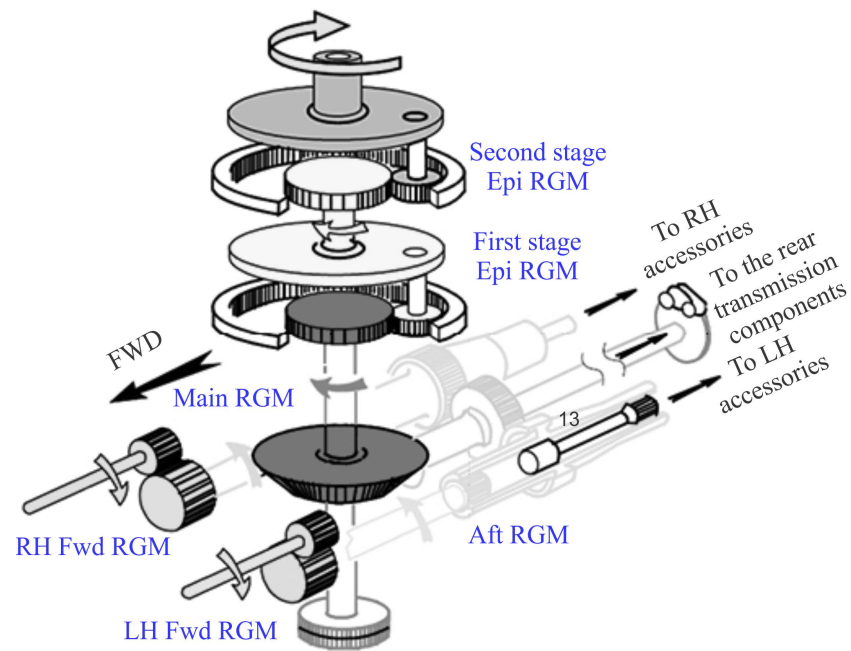

Fig. 1: The sketch of helicopter MGB internal parts.

hand (LH) and right hand (RH) forward (Fwd) RGMs, after (Aft) RGM, main RGM and 2-stage epicyclic (Epi) RGM, as shown in figure 1. It converts the engine power from high speed (typically 24,000 rpm) and low torque to low speed (typically $265 \mathrm{rpm}$ ) and high torque to drive the main rotor and tail rotor systems. The bevel gear reduces the rotational speed to 2,405 rpm and changes the direction of the transmission to drive the 2-stage Epi RGM. The first and second stage contains 8 and 9 planets gears, respectively. The planet gear speed of first and second stage is $2970 \mathrm{rpm}$ and $1119 \mathrm{rpm}$ respectively.

The test was devised under three conditions: an undamaged planet bearing, a slightly damaged planet bearing and a heavily damaged planet bearing. The defect was seeded on one of the planetary gears bearing of the second epicyclic stage (figure 2(a)). The slightly damage was simulated by machining a rectangular slot of $10 \mathrm{~mm}$ wide and $0.3 \mathrm{~mm}$ deep across the bearing outer race, as shown in figure 2(b). The heavily damage was the combination of both damaged an outer race (about $30 \mathrm{~mm}$ wide, $0.3 \mathrm{~mm}$ deep) and inner race (natural spalling around half of the circumference, as shown in figure 2(c). The the bearing outer race defect (ORD) frequency $f_{O R D}$ calculated using the equation

$$
f_{O R D}=\frac{N}{2} \frac{S}{60}\left(1-\frac{d}{D} \cos \alpha\right),
$$

where $N=13$ is the number of rollers, $S=1119 \mathrm{rpm}$ is planet gear speed of the second stage Epi RGM, $d=12.5 \mathrm{~mm}$ is the diameter of roller, $D=63.65 \mathrm{~mm}$ is the pitch diameter and $\alpha=0$ is the nominal contact angle. The calculated $f_{O R D}$ is equal to $97.42 \mathrm{~Hz}$.

Most commercial AE sensors are assembled in sturdy metal case. The metal case might cause serious problems if sensor dislodges inside gearbox. To this end, piezoelectric wafer active sensor (PWAS) is the most suitable AE sensor for insitu applications. The normal operational temperature range of gearbox is $-10^{\circ} \mathrm{C}$. to $+130^{\circ} \mathrm{C}$. Hence, the OMEGADYNE

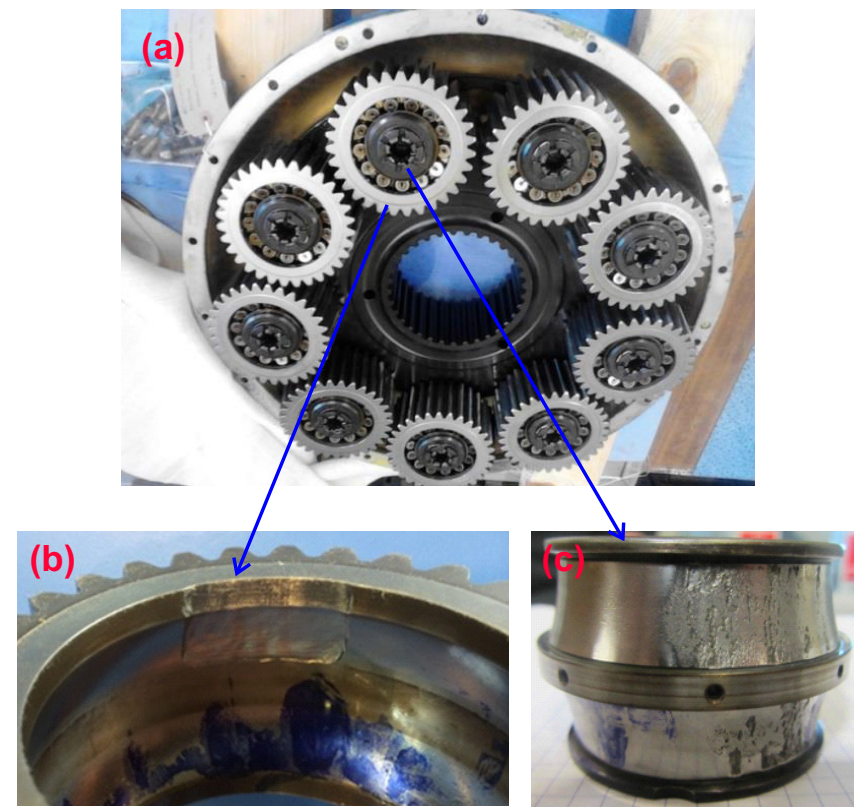

Fig. 2: (a) Second stage epicyclic gears (b) Slot across the bearing outer race; (c) Inner race natural spalling.

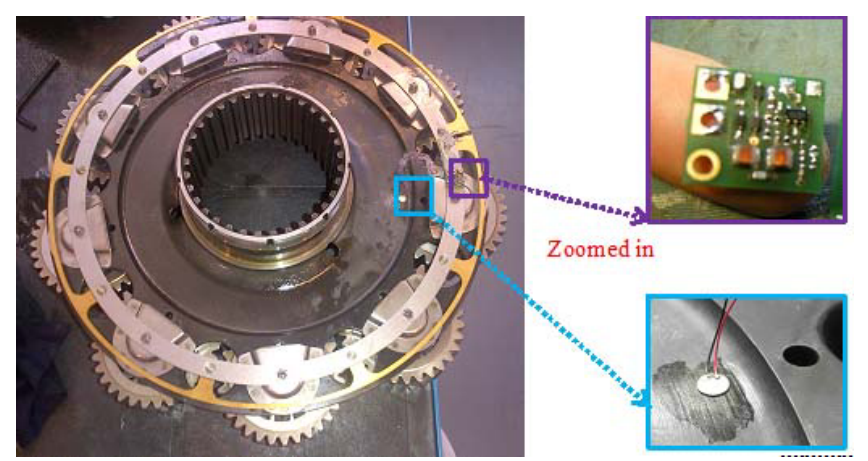

Fig. 3: PWAS located on the dish of planet carrier. Insert: Sensor board (right top); PWAS (right bottom)

TT300 cement (working limit of $200^{\circ} \mathrm{C}$ ) was used to bond the sensor to the planet carrier, as shown in figure 3 .

The internal AE sensor was connected to the internal signal conditioning board, transmitted wirelessly, demodulated then passed to the data acquisition system over BNC cable. The wireless transmission is realized by using two coils, moving coil and stationary coil. The moving coil comprised two single turn brass copper tracks of approximately $400 \mathrm{~mm}$. The moving coil and the signal conditioning board were attached to a circular mounting ring which was in turn mounted on top of the oil caps on the second stage planet carrier. The stationary coil was suspended from two clamping rings which were attached to the top case of the gearbox with a spacer through the holes to retain location. The acquisition card was a NI 6115 card, connected to a BNC 2110 connector block. The signal was sampled at $5 \mathrm{MHz}$. 
TABLE I: Test conditions

\begin{tabular}{|l|l|l|l|l|}
\hline & $\begin{array}{l}\text { Load } \\
\text { Condition } \\
(\mathrm{kW})\end{array}$ & $\begin{array}{l}\text { Rotor } \\
\text { speed } \\
(\mathrm{RPM})\end{array}$ & $\begin{array}{l}\text { Left input } \\
\text { torque } \\
(\mathrm{Nm})\end{array}$ & $\begin{array}{l}\text { Right in- } \\
\text { put torque } \\
(\mathrm{Nm})\end{array}$ \\
\hline $\begin{array}{l}\text { 80\% Max contin- } \\
\text { uous power }\end{array}$ & 936 & 265 & 196 & 196 \\
\hline $\begin{array}{l}100 \% \text { Max con- } \\
\text { tinuous power }\end{array}$ & 1300 & 265 & 272 & 272 \\
\hline $\begin{array}{l}110 \% \text { Max take- } \\
\text { off power }\end{array}$ & 1760 & 265 & 368 & 368 \\
\hline
\end{tabular}

\section{EXPERIMENTAL RESULTS AND DISCUSSION}

Three fault conditions were tested under three load conditions, $80 \%$ and $100 \%$ of maximum continuous power and $110 \%$ of maximum take-off power. The load condition, rotor speed, left and right input torque are listed in table I.

The measured $\mathrm{AE}$ signal was processed to estimate the power spectrum of the AE signal for both damaged and faultfree conditions. The spectral kurtosis (SK) analysis was firstly utilized to obtain the frequency bands and center frequencies of captured AE signal which were then used to undertake the envelope analysis. The basic principle of SK analysis is to determine the kurtosis at different frequency bands in order to identify the energy distribution of the signal and determine where the high impact energy (transient events) are located in the frequency domain. It has been demonstrated to be effective even in the presence of strong additive noise [5]. The calculated center frequency, bandwidth and kurtosis of AE signal are tabulated in table II. It can be seen that there are no noticeable differences of maximum kurtosis under fault-free, minor damage and major damage conditions. Furthermore, the center frequency, bandwidth and kurtosis are identical for each fault level at different load conditions. This results from the fact that the fault will excite certain resonance frequency and the excitation is due to the bearing forces not to the loading condition applied. Thus, the same bearing force will excite same frequency ranges. The center frequency and bandwidth are useful to design band pass filter to improve $\mathrm{AE}$ signal to noise ratio [6], [7]

Envelope analysis has been extensively utilized in vibration analysis for diagnosing bearings and gearboxes defects [8], [9]. Envelope analysis is based on the principle of identifying frequencies of the impacts, which results from defects excited resonance. Vibration signal is firstly filtered at high frequencies (structural resonance frequencies). Then, the signal is passed through an envelope detector and a low pass filter. Using the same approach, the enveloped AE signal is presented in the frequency domain to identify fault frequency components. Figure 4 shows enveloped spectra of AE signal recorded from fault-free, minor and major bearing defects at $80 \%$ maximum continuous power, respectively. Observations of figures (b) and (c) clearly indicate the presence of the bearing ORD frequency $f_{O R D}(96 \mathrm{~Hz})$ and its harmonic $(192 \mathrm{~Hz})$ for both minor and major damages. The results of $100 \%$ maximum
TABLE II: Filter characteristics estimated based on SK for AE signals

\begin{tabular}{|c|c|c|c|c|}
\hline Loadcondition & Case & $\begin{array}{l}\text { Center } \\
\text { frequency } \\
(\mathrm{Hz})\end{array}$ & $\begin{array}{l}\text { Band } \\
\text { Width } \\
(\mathrm{Hz})\end{array}$ & Kurtosis \\
\hline \multirow{3}{*}{$\begin{array}{l}80 \% \text { of max con- } \\
\text { tinuous power }\end{array}$} & Fault-free & 1093750 & 312500 & 12 \\
\hline & $\begin{array}{l}\text { Minor } \\
\text { damage }\end{array}$ & 234375 & 52083 & 9 \\
\hline & $\begin{array}{l}\text { Major } \\
\text { damage }\end{array}$ & 312500 & 208333 & 7.9 \\
\hline \multirow{3}{*}{$\begin{array}{l}100 \% \text { of } \max \\
\text { continuous power }\end{array}$} & Fault-free & 1093750 & 312500 & 12 \\
\hline & $\begin{array}{l}\text { Minor } \\
\text { damage }\end{array}$ & 234375 & 52083 & 9 \\
\hline & $\begin{array}{l}\text { Major } \\
\text { damage }\end{array}$ & 312500 & 208333 & 7.9 \\
\hline \multirow{3}{*}{$\begin{array}{l}110 \% \text { of } \max \\
\text { continuous power }\end{array}$} & Fault-free & 1093750 & 312500 & 12 \\
\hline & $\begin{array}{l}\text { Minor } \\
\text { damage }\end{array}$ & 234375 & 52083 & 9 \\
\hline & $\begin{array}{l}\text { Major } \\
\text { damage }\end{array}$ & 312500 & 208333 & 7.9 \\
\hline
\end{tabular}
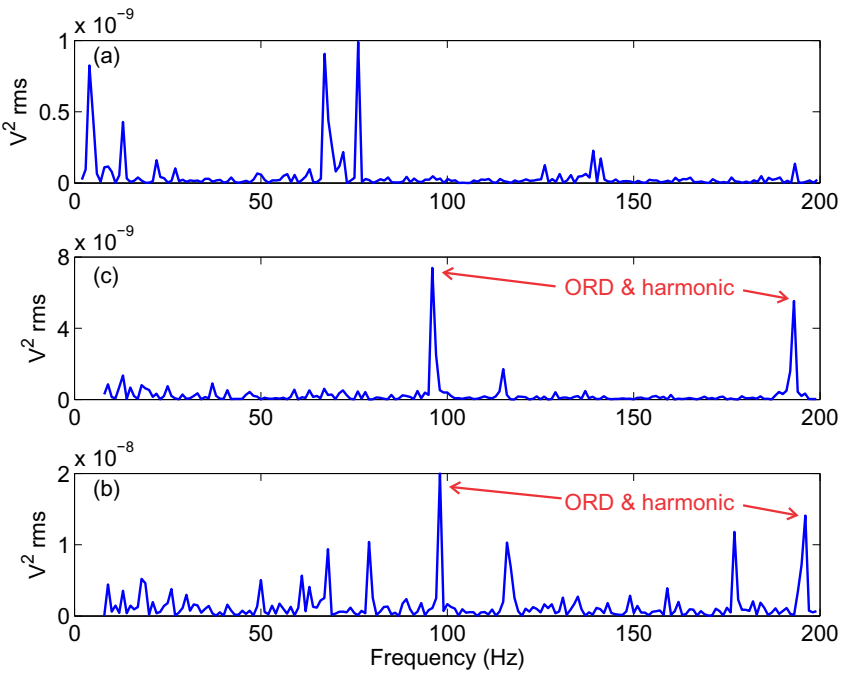

Fig. 4: Enveloped spectra of AE signal (a) fault-free, (b) minor and (c) major bearing defects at $80 \%$ maximum continuous power.

continuous power and $110 \%$ maximum take-off power conditions are shown in figures 5 and 6 , respectively. The results indicated that it is feasible to detect bearing faults of different severity and load condition. In the current stage, the visual observation has to be used to determine the appearance of bearing outer race defect frequency and its harmonics. The fast determination of faults related frequencies and their threshold is under investigation.

\section{CONCLUSION}

The AE sensor was used in this research to detect seeded bearing faults in a helicopter MGB. In order to increase signal to noise level under strong background noise, the PWAS was 

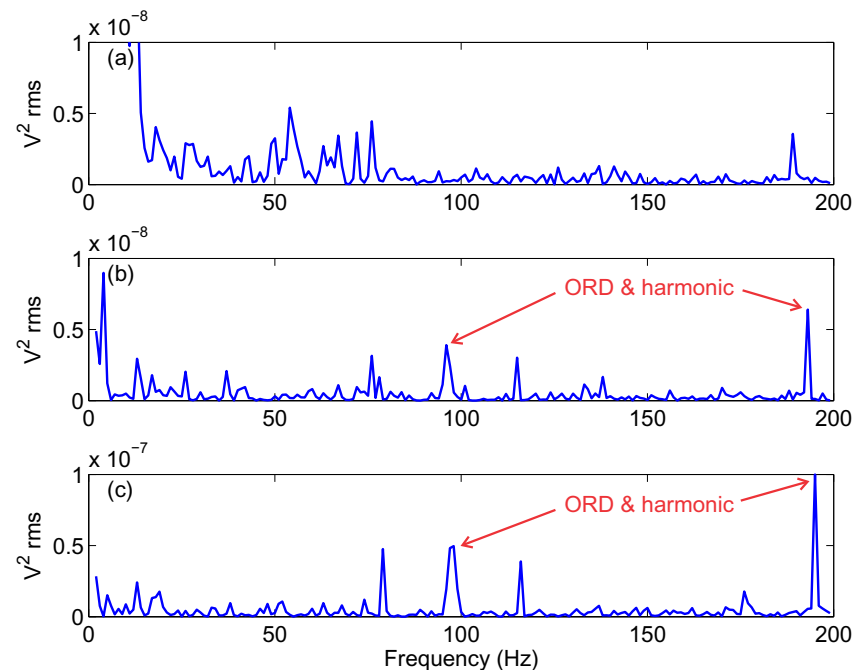

Fig. 5: Enveloped spectra of AE signal (a) fault-free, (b) minor and (c) major bearing defects at $100 \%$ maximum continuous power.
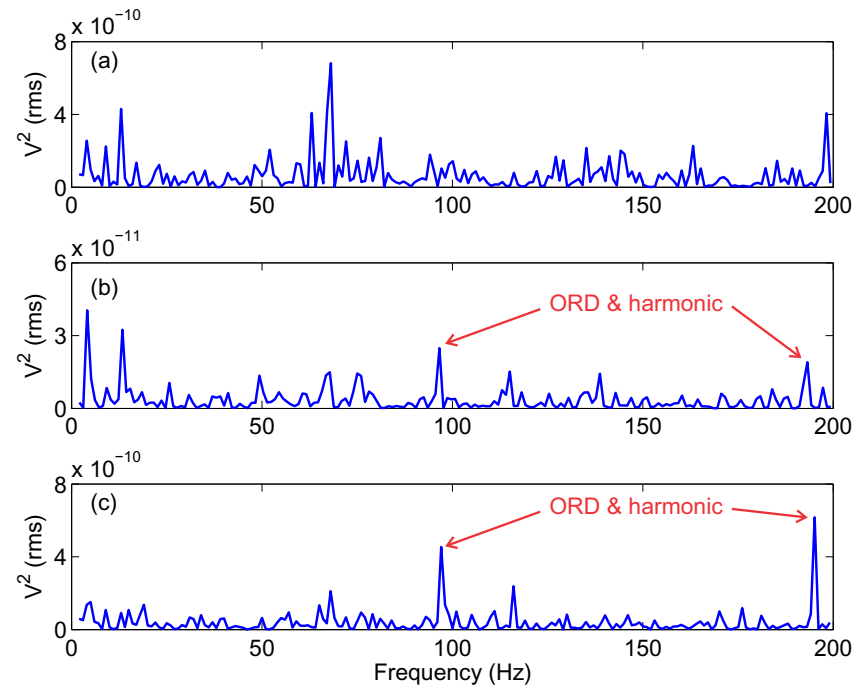

Fig. 6: Enveloped spectra of AE signal (a) fault-free, (b) minor and (c) major bearing defects at $110 \%$ maximum take-off power.

attached on the surface the dish of planet carrier. The complex wiring was avoided by using advanced wireless transmission technique. The observations of AE enveloped spectra showed that $\mathrm{AE}$ analysis was able to identify the presence of the bearing outer race defect frequency and its harmonic for both minor and major damaged under three different loading conditions.

\section{REFERENCES}

[1] Department for Transport, "Report on the accident to aerospatiale (Eurrocopter) AS332 L2 Super Puma, registration G-REDL $11 \mathrm{~nm}$ NE of Peterhead Scotland, on 1 April 2009," 2011.

[2] N. Goodman, A. Bayoumi, V. Blechertas, R. Shah, and Y. Shin, "CBM component testing at the University of South Carolina: AH-64 tail rotor gearbox studies," in American Helicopter Society Technical Specialists Meeting on Condition Based Maintenance, 2009.

[3] D. Mba, "Prognostic opportunities offered by acoustic emission for monitoring bearings and gearboxes," in Twelfth International Congress on Sound and vibration, Lisbon, Portugal, 2005.

[4] D. Mba and R. B. Rao, "Development of acoustic emission technology for condition monitoring and diagnosis of rotating machines; bearings, pumps, gearboxes, engines and rotating structures," The Shock and Vibration Digest, vol. 38, no. 1, pp. 3-16, 2006.

[5] J. Antoni and R. Randall, "The spectral kurtosis: application to the vibratory surveillance and diagnostics of rotating machines," Mechanical Systems and Signal Processing, vol. 20, no. 2, pp. 308-331, 2006.

[6] C. Ruiz-Cárcel, E. Hernani-Ros, Y. Cao, and D. Mba, "Use of spectral kurtosis for improving signal to noise ratio of acoustic emission signal from defective bearings," Journal of Failure Analysis and Prevention, vol. 14, no. 3, pp. 363-371, 2014.

[7] B. Eftekharnejad, M. Carrasco, B. Charnley, and D. Mba, "The application of spectral kurtosis on acoustic emission and vibrations from a defective bearing," Mechanical Systems and Signal Processing, vol. 25, no. 1, pp. 266-284, 2011.

[8] W. Wang, "Early detection of gear tooth cracking using the resonance demodulation technique," Mechanical Systems and Signal Processing, vol. 15, no. 5, pp. 887 - 903, 2001.

[9] R. Randall and J. Antoni, "Rolling element bearing diagnosticsa tutorial," Mechanical Systems and Signal Processing, vol. 25, no. 2, pp. 485 - 520, 2011. 